\title{
Shiftwork Organization
}

\author{
Giovanni Costa, Eleonora Tommasi, \\ Leonardo Giovannini, and Nicola Mucci
}

\subsection{Introduction to Shift Work}

\subsubsection{Definition and Main Features}

The correct organization of health worker shiftwork is essential to ensure continuous 24-h patient care. Healthcare is the perfect example of the "24-h society," whose milestones are the various types of shift work (night work, split shifts, on-call work, part-time work, irregular and flexible working hours) and new technologies. In general, "shiftwork" means any structure of work in which the operating time of a company is extended beyond the usual 8 or $9 \mathrm{~h}$ (typically between 7-8 a.m. and 5-6 p.m.), to cover the entire $24 \mathrm{~h}$, through the alternation of different groups of workers [1,2].

To ensure 24-h coverage, shift work must also include night work which, according to International Labour Organization Convention No. 171 [3], is defined as "all work which is performed during a period of not less than seven consecutive hours, including the interval from

\footnotetext{
G. Costa

Department of Clinical Sciences and Community

Health, University of Milano, Milan, Italy

e-mail: giovanni.costa@unimi.it

E. Tommasi · L. Giovannini · N. Mucci $(\bowtie)$

Department of Experimental and Clinical Medicine,

University of Florence, Florence, Italy

e-mail: eleonora.tommasi@unifi.it;

leonardo.giovannini@unifi.it; nicola.mucci@unifi.it
}

midnight to 5 a.m. (night time)." The European Directive 2003/88/EC [4] defines a "night worker" as "(a) any worker who, during the night, works at least three hours of his daily working time as a normal course; (b) any worker who works a certain proportion of his annual working time, as defined at the choice of the Member State concerned."

Shift scheduling may differ with respect to various parameters including:

- Duration of duty period: predominantly ranging from 6 to 8 or $9 \mathrm{~h}$, but it can last up to $12 \mathrm{~h}$ or more, or be reduced to $4 \mathrm{~h}$ (in the case of part-time work).

- Semicontinuous or continuous rota systems: depending on the inclusion of weekends or Sundays.

- Presence and frequency of work during the "nighttime."

- Number and type of shifts: mainly two shifts (morning and afternoon) or three shifts (including the night) of 7-9 h, or four shifts of $6 \mathrm{~h}$ (morning, afternoon, evening, night, in the so-called "6 6 6" shift system).

- Start and end times of each shift: for example, morning shift (starting after 03:00 and ending before 18:00), day shift (starting after 08:00 and ending before 18:00), evening shift (starting at any time between 18:00 and 23:00 and not categorized as a night shift), night ( $\geq 3 \mathrm{~h}$ between 23:00 and 06:00). 
- Direction of shift rotation: clockwise or phasedelayed (morning-afternoon-night), counterclockwise or phase-advanced (afternoon-morning-night).

- Speed of rotation among shifts: fast (every 1-3 days), intermediate (every 4-6 days), slow ( 7 or more days), null (in the case of fixed shifts).

- Regularity/irregularity and length of the entire shift cycle (i.e., from 5 days up to 6 months or more).

Shift work can have adverse effects on the health and well-being of the worker who must be operative at all times and on days off. In particular, shift work causes significant interference in the different domains of human life (biological, behavioral, social) and alters the psychophysical balance of a person, in particular: (1) the perturbation of circadian rhythms; (2) a reduction in vigilance and performance, leading to a consequently greater risk of errors and accidents; (3) adverse health effects both in the short-term (sleep, digestive, mental and menstrual disorders) and in the medium- to long-term (increased gastrointestinal, neuropsychic, metabolic, cardiovascular diseases); (4) difficulties in maintaining social roles, which have negative consequences on interpersonal relationships and family care. Several studies suggest that shiftwork also increases the risk of breast, prostate, and colorectal cancers.

Shift workers must be adequately informed about this occupational risk factor and must be guaranteed adequate organization of working times based on proven ergonomic criteria as well as appropriate compensatory measures to mitigate adverse effects.

\subsubsection{Chronobiological Aspects}

"Circadian rhythm" describes the physiological oscillations occurring in biological functions over the course of $24 \mathrm{~h}$. The word "circadian" comes from Latin, where "circa" means "around" and "diem" means "day." In humans, the circadian master clock resides in the suprachiasmatic nucleus of the anterior hypothalamus and is syn- chronized by environmental factors, in particular light/dark alternation. By way of the retinohypothalamic tract, external light influences the expression of the CLOCK and BMAL1 genes, which are the main regulators of the periodic oscillations that occur during the light/dark cycle. The binding of CLOCK and BMAL1 activates other genes such as the Period genes that are also responsible for the physiological oscillation of the circadian rhythm by means of an inhibitory feedback loop. Period genes encode for the PER protein, whose level rises during the night and decreases during the day. Based on the light stimuli received and the genes activated as a result, the suprachiasmatic nucleus regulates the secretion of melatonin from the pineal gland: melatonin levels increase during the dark of night and decrease under the exposure to light during the day [5].

Shift work, in particular night work, modifies human exposure to the light/dark cycle and consequently the normal circadian oscillation of biological functions. This alteration involves a flattening of the amplitude and a shift of the acrophase of circadian rhythms, the extent of which depends on the number of consecutive night shifts and the direction of rotation, clockwise or counterclockwise, of the on-duty periods. The type of shift work, whether rotating or fixed, can also affect the oscillation of circadian rhythms. Workers involved in continuously rotating shifts, the most widely used in the health sector, are forced to adapt as quickly as possible to changing work times, resulting in significant work-stress. Fixed-shift workers, on the other hand, are more likely to keep their sleep/wake cycle stable, provided they keep a consistent schedule even on days off.

\subsection{Effects of Shift Work on Worker Health and Impact on Patient Safety}

\subsubsection{Sleep Deprivation and Vigilance}

The disturbance of the psychobiological functions, linked to the modification of the sleep/wake cycle, plays an important role in 
influencing work ability. Shift workers can suffer from a series of symptoms commonly known as "jet-lag syndrome," characterized by fatigue, drowsiness, insomnia, digestive troubles, and the slowing down of mental functions and performance.

The timing of shifts (especially night and early-morning), the environmental conditions, and workers' lifestyles can negatively affect both quantity and quality of sleep. After the night shift, a worker should be placed in favorable conditions for psychophysical recovery. However, falling asleep and sleeping longer are very difficult due to environmental interference such as light and noise. Sleep is generally reduced by about 2-4 h: in particular, phase 2 of non-rapid eye movement sleep (NREM) and rapid eye movement sleep (REM) are disturbed. The REM phase is also particularly reduced by the earlymorning shift (starting at 6 a.m. or earlier) because of a truncation of the last part of the sleep cycle; moreover, this advanced waking time usually causes excessive daytime sleepiness during the waking period. The direction of rotation of shifts can also influence sleep patterns and circadian rhythms: clockwise-rotating shift schedules are less disruptive than counterclockwise ones. In very quickly rotating shifts for example, the intervals between shifts rotating clockwise $(1 \mathrm{M}-1 \mathrm{~A}-1 \mathrm{~N})$ are longer (always $24 \mathrm{~h}$ ) than those between shifts rotating according to a counterclockwise system $(1 \mathrm{~A}-1 \mathrm{M}-1 \mathrm{~N})$ which places the morning shift immediately after the afternoon shift and before the night shift of the very same day ("quick return"): in the latter case, rest intervals between shifts are very short (only $8 \mathrm{~h}$ ), thus implying the truncation of sleep preceding the morning shift and the possibility of only a very short sleep or nap before the night shift [6].

It is well known that sleepiness, sleep deprivation, chronic fatigue, and fluctuations in vigilance are key factors in creating the conditions that lead to human errors and accidents through interactions with other organizational factors, such as environmental conditions, workload, job content, and time pressure. Insomnia, one of the core symptoms of shift work disorder, has a prevalence of about $6 \%$ in the general population and between $29 \%$ and $38 \%$ in shift workers [7].
Symptoms include difficulties falling asleep, reduced sleep duration, frequent waking, and an intense preoccupation with the act of sleeping itself.

Fatigue, drowsiness, and insomnia resulting from a disturbed sleep-wake cycle can manifest themselves as the so-called "shift work sleep disorder," which negatively affects physical and mental health, quality of life, performance, and productivity. A study by Drake et al. [8] investigating 2570 US workers aged 18-65 years reported that $14 \%$ of night workers and $8 \%$ of rotating shift workers met the criteria for shift work sleep disorder. Such individuals had significantly higher rates of ulcers (odds ratio of 4.18), sleepiness-related accidents, absenteeism, and depression, and missed family and social activities more frequently compared to shift workers who did not meet the criteria.

Concerning personal characteristics, Kalmbach et al. [9] reported that in a group of normal sleeping, non-shift workers, the chances of developing shift work disorder after transitioning to rotating shifts were over five times greater for highly sleep-sensitive individuals. In a longitudinal study including 1533 Norwegian nurses, Waage et al. [10] showed that the risk of developing a shift work disorder was significantly associated with the number of night shifts worked in the previous year, the Epworth sleepiness score, the use of melatonin, the use of bright light therapy, and symptoms of depression.

\subsubsection{Interference in Performance Efficiency and Patient Safety}

Shift and night work, as well as prolonged and/or irregular working hours, are also risk factors for patient safety, a fact well documented by many epidemiological studies. The working conditions of the night shift differ from those of the day shift. In particular, the night shift involves fewer employees who have to take care of many patients. The increased workload and the alteration of the sleep-wake rhythm increases the risk of making clinical errors.

Studies in the industrial sector have shown that risk grows with the number of consecutive 
night shifts $(6 \%$ increase for the second night, $17 \%$ for the third, and $36 \%$ for the fourth) and with the lengthening of work shifts, noting an exponential increase in the occurrence of accidents after the eighth hour of work and estimating a doubling of the risk for 12-h shifts compared to 8-h shifts, for which there is no corresponding reduction in workload or introduction of adequate breaks.

Similar results are also reported for the hospital workers, including a higher relative risk of accidents in afternoon and night shifts, resulting in longer periods of absence, as well as reduced levels of attention and vigilance and increased error associated with long shifts (24 h or more) [11-13]. On the other hand, it is also known that a significant improvement of these outcomes can come from limiting the length of work shifts $[14,15]$.

According to a study of 2737 US medical residents [16], the incidence of at least one major mistake was $3.8 \%, 9.8 \%$, and $16 \%$, in the case of 0 shifts, 1-4 shifts, and more than 4 shifts of prolonged duration (32 h on average), respectively, with a 300\% increase in preventable adverse events due to fatigue and/or sleep deprivation resulting in the death of the patient. Other core symptoms of fatigue are exhaustion, tiredness, and lethargy, resulting in loss of efficiency, difficulty in concentrating, as well as a decrease in productivity and safety at work.

In the case of nurses, too, an increase has been documented in the occurrence of errors, that jeopardize patient safety, dependent on the duration of a shift beyond $8 \mathrm{~h}$, overtime, and night work shifts [17-19]. In addition, other studies have shown that, when coupled with high patient turnover, extended shifts or a reduced number of staff are associated with an increase in hospital mortality. In addition, other studies reveal significant association between increased hospital mortality rates and extended shifts or reduced staff along with high patient turnover (YES IT IS) [20, 21].

A very recent national survey on work patterns and fatigue-related outcomes carried out on 3133 nurses of 6 practice hospital areas (child health including neonatology, cardiac care/intensive care, emergency and trauma, inpatient men- tal health, medical, and surgical nursing) in New Zealand showed that $30.8 \%$ of errors in the previous 6 months were fatigue-related while $64 \%$ of responders reported having felt sleepy at the wheel in the previous 12 months. Fatigue-related outcomes were associated with shift timing and sleep. Risk increased with more night shifts and decreased with more nights of sleep between 11 p.m. and 7 a.m. during which nurses had enough sleep to feel fully rested. Risk also increased with roster changes and more shift extensions greater than $30 \mathrm{~min}$, and decreased with more flexibility regarding shifts [22].

\subsubsection{Health Disorders}

The literature in recent years shows that shift work can cause serious medium- and long-term effects on the worker health due to the disruption of physiological circadian rhythms [1, 23]). Hence, the socioeconomic and health-related consequences of sleep and circadian rhythm disorders in shift workers, such as absenteeism and mood disorders, should likewise not be underestimated [24].

Irritability, nervousness, and anxiety are frequent complaints from shift workers, relating to more stressful working conditions. In association with persistent disruption of circadian rhythms and sleep deficit, they may lead to mood disorders, chronic anxiety, and/or depression, fostering absenteeism and often requiring the administration of sedatives and hypnotics [25].

After the aforementioned sleep troubles, gastrointestinal disorders are the most frequent morbidities found among shift workers. In particular, the risk of gastroduodenitis, peptic ulcer, and irritable bowel syndrome is two to five times higher for shift and night workers [26]. The mismatch between circadian phases of the gastrointestinal tract (i.e., gastric, bile, and pancreatic secretions, intestinal mobility, hunger and satiety hormones) and meal times is one of the causes for this increased prevalence among shift workers, who are most frequently forced to consume "junk food," which are pre-packaged and more caloric, and "pep" and soft drinks [27]. 
Many epidemiological studies have demonstrated a significant association between shift work and metabolic syndrome [28], insulin resistance, and type 2 diabetes [29, 30].

Moreover, according to several authors, shift workers have a $40 \%$ higher risk than day workers of suffering from ischemic heart disease [31, 32], relating to circadian disruption along with disturbed cardiac autonomic control and detrimental lifestyle changes, such as obesity and smoking [33]. A recent meta-analysis by Manohar et al. [34] also reported a significant association between hypertension and rotating shift work.

Night shift work negatively affects female fertility and reproductive health and is associated with an increased risk of adverse pregnancy outcomes such as miscarriage and impaired fetal development, including pre-term birth and low birth weight [35]. In 2007, "shift work involving circadian disruption" was classified as "probably carcinogenic to humans" (Group 2A) by the International Agency for Research on Cancer (IARC) on the basis of sufficient evidence in animal models and limited evidence in humans, in particular for breast cancer. A positive association between high-intensity, long-duration night shift work and breast cancer has also been reported in large populations of nurses [36]. Experimental animal and cellular studies found immunosuppression, chronic inflammation, and cell proliferation caused by the disruption of the light-dark cycle. According to recent epidemiological studies, weaker evidence is also emerging for colorectal and prostate cancer: this has lead the IARC to confirm very recently its assessment of night shift work as a probable carcinogen [37].

\subsection{Preventive Actions and Recommendations}

\subsubsection{Ergonomic Criteria for the Organization of Shift Schedules}

Healthcare companies must also consider the well-being of their employees when organizing shift work. Shifts must be planned based on ergo- nomic criteria that protect the psychophysical integrity and social well-being of workers. These criteria must take into account biological adaptation, work performance, health status, and personal and social problems, and can be summarized as follows $[38,39]$ :

- The amount of night work and the number of consecutive night shifts should be reduced as much as possible (2-3 at most) to limit interference with circadian rhythms and sleep.

- Quickly rotating shift systems should be chosen over slowly rotating ones, since they interfere less with circadian rhythms and minimize the extent of any cumulative sleep deficit.

- Clockwise rotation (morning-afternoon-night) should be preferred to counterclockwise rotation (afternoon-morning-night) since it is better adapted to endogenous circadian rhythms (which show a periodicity slightly longer than $24 \mathrm{~h}$ in "free-running" experiments), avoids quick changeovers (e.g., having morning and night shifts within the same day), and allows for longer rest periods for immediate recovery from fatigue and sleep deficit.

- Setting the start of morning shifts too early should be avoided in order to reduce the truncation of sleep (of the REM phase in particular) and the consequent sleepiness and risk of error.

- Prolonged work shifts (9-12 h) should only be considered when the workload is suitable, adequate pauses may be taken, and the shift system is designed to minimize the accumulation of fatigue as well as the exposure to toxic substances.

- Shift cycles should be as regular as possible and should ensure as many weekends free as possible, in order to allow workers to better plan and enjoy their leisure and social time.

- Fixed night work should be implemented only for particular work situations, which require a complete adjustment to night work to ensure the highest levels of safety.

- Flexible working time arrangements should be promoted in order to meet workers' needs and preferences. 
However, there doesn't exist a "best" shift system that can be recommended across the board. Each shift-based work schedule should be planned around and tailored to the different job activities and demands involved, as well as the specific traits, social habits, and personal backgrounds of the workers involved. Workers must participate in the analysis, design, and implementation of the shift system chosen. This is important for motivating workers and improving their psychophysical tolerance: indeed, shift schedules often fail because they do not reflect the conditions and needs of workers. On the other hand, workers sometimes prefer less favorable shift patterns (i.e., 12-h shifts or counterclockwise rotation) in order to have longer rest periods between cycles. As previously mentioned, in several cases the rapid transition from morning to night shift in the same day, in particular waking early in the morning, prefigures an extremely stressful and risky condition.

The duration of work shifts should be adjusted according to workload and the type of task, as well as the number of workers available. Jobs requiring high levels of vigilance and physical activity (i.e., emergency and intensive care units) should have shorter shifts while, on the other hand, shifts may be longer for jobs with a lighter workload (i.e., basic assistance or support activities) or jobs during which workers can take breaks.

\subsubsection{Other Organizational Aspects}

When introducing or modifying a shift scheme, an effective methodology should follow precise steps, including in particular:

1. A preliminary, general plan taking into account the various conditions at play, such as legislative and contractual provisions, service and/or production requirements, working conditions.

2. A careful analysis of the traits of the persons involved, with a focus on demographic aspects (e.g., age, gender), workloads in the different shifts, risk factors, personal conditions (e.g., family and social status, commuting).
3. The structure of the shift schedule based on the previously mentioned ergonomic criteria.

4. The shift system's introduction and a verification of the degree of acceptability by a sample group of workers for a given period, including the recording of appropriate indicators (e.g., subjective assessment, working behavior, absenteeism, errors).

5. The final implementation of the new shift system after adequate adjustments addressing any indications emerging from the previous phase.

The planning of shift work in hospitals is complex because it involves multiple organizational aspects based on the type of assistance provided (e.g., intensive care, medical, surgical, laboratory, and specialist services) and the operational standards in terms of the staff/patient ratio, the type of intervention, and the quantity and type of professionals available and/or necessary in each shift. Various interventions aimed at compensating for the inconveniences caused by shift work have been proposed and adopted in recent years, often in very different and empirical ways depending on the different working conditions and specific, company-wide problems. According to Thierry [40], these interventions can be divided into two categories:

(a) The "counterweights," intended solely to compensate for inconveniences or disturbances caused by the shift system. One that is usually (and often uniquely) adopted is the increase in remuneration for work performed at night and during holidays. This constitutes a simple translation of the various aspects of the problem into monetary terms, which often has no direct connection to their specificity or seriousness, as the increase in remuneration may differ considerably as a function of contractual rules, trade union power, economic conditions, and company production needs. Other, more useful "counterweights" represent actions aimed at improving working conditions such as environmental hygiene, workload, and pace.

(b) The "counter-values," aiming at reducing or eliminating the causes of adverse conse- 
quences or inconveniences. Among these, the following must be reported at an organizational level: the reduction of night work by limiting the number of night shifts during the year and/or reducing the duration of the shift itself; the introduction of scheduled breaks providing an opportunity to enjoy hot meals and take short naps; a higher number of compensatory rest days or holidays proportional to the number of night shifts worked; the provision of adequate social services (e.g., transportation, nursery schools, kindergartens) through appropriate agreements with local authorities and commercial organizations; the possibility to switch to day work temporarily, at regular intervals, and/or permanently after a certain number of years assigned to the night shift or at a certain age.

\subsection{Some Considerations for Resident Doctors}

The path to becoming a doctor is notoriously difficult. Medical residencies are institutional internships and are therefore structured to serve the dual, often competing, purposes of training new generations of professionals while responding to the working needs of a hospital. Despite improvements brought about by good-faith efforts, the physical and emotional demands on residents have few comparisons in modern society. Some of these pressures are inherent to the nature of the profession. Most people cannot imagine a workday when a mental lapse or an error in judgment can deprive another person of their hearing, brain functioning, or even life. But those in the medical profession are expected to grin and bear it, and come back the next morning for their 6 a.m. shift.

Other demands are less easily explicable. Residents in the USA are expected to spend up to $80 \mathrm{~h}$ a week in the hospital and endure single shifts that routinely last up to $28 \mathrm{~h}$, with such workdays required on average about four times a month [41]. Overall, residents usually work more than twice as many hours annually as their peers in other white-collar professions, such as attorneys in corporate law firms, and face a grueling schedule that potentially puts both caregivers and patients at risk. In Europe, on the other hand, residents are subject to a maximum workweek of $48 \mathrm{~h}$, with no "apparent" harm to patient care or to the educational component of residencies. This workweek policy in Europe is just considered to be a legal formality, as the extension of work hours is common practice in any hospital and clinical ward. This disregard for the law, due to economical and organizational deficiencies, is not just an injustice to the worker, but also a serious clinical risk to patient safety. Residents are a cheap source of skilled labor that can fill gaps in staff coverage while being paid a fixed, modest salary. Hence the non-compliance with the European directive is something even more important in the context of residency. Residents are usually the last step in the health ladder and the more expendable.

This misconduct is so deeply rooted within the health system not only by systemic problems (such as a shortage of trained medical doctors, a lack of nurses, and difficulties in logistics) but also because of an overreliance on residents. In fact, usually owing to their willingness to learn more and learn faster, residents choose to work more than dictated by the law, without concern for their condition and, unfortunately, for patient safety. Surely there is a bigger problem among US residents in particular, seeing as, before 2011, it was routine for them to spend 100 or even $120 \mathrm{~h}$ a week in the hospital, with single shifts extending up to $48 \mathrm{~h}$ and beyond. In 2011, the Accreditation Council for Graduate Medical Education established additional restrictions [42] among other things, by reducing the maximum shift duration to $16 \mathrm{~h}$ for first-year residents (also known as "interns") and to $28 \mathrm{~h}$ for more experienced residents [43]. But looking closely at the effects of the new rules, it is unclear how much residents' working lives have actually changed. Averaging 80-h workweeks and regularly putting in 28-h shifts is still brutal by any measure. On the other hand, in 2017, the limit placed by the 2011 law was reverted back to $24 \mathrm{~h}$ per shift for first-year surgery residents. This change was justified by the publication of the Bilimoria study [44], which claimed that longer shifts may be better for patients and for the training of young 
doctors. The findings of this article have been confirmed by another article written about residents of internal medicine and published in 2019, in which it was shown that the exposure of internists to working time reforms during their residency was not associated with post-training differences in patient mortality, readmissions, or costs of care [45].

\section{References}

1. Costa G. Shift work and health: current problems and preventive actions. Safety Health Work. 2010;1:11223. https://doi.org/10.5491/SHAW.2010.1.2.112.

2. Costa G. Introduction to problems of shift work. In: Iskra-Golec I, Barnes-Farrell J, Bohle P, editors. Social and family issues in shift work and non standard working hours. Switzerland: Springer International Publishing; 2016;19-35.

3. ILO International Labour Organization. C171-night work convention, 1990 (No. 171). 1990. https:// www.ilo.org/dyn/normlex/en/f?p=NORMLEXPUB: 12100:0::NO::P12100_INSTRUMENT_ID:312316. Accessed 30 Sept 2019.

4. European Parliament and Council. Directive 2003/88/EC of 4 November 2003 concerning certain aspects of the organisation of working time. 2003. https://eur-lex.europa.eu/legal-content/EN/ ALL/?uri=CELEX:32003L0088. Accessed 30 Sept 2019.

5. Seifalian A, Hart A. Circadian rhythms: will it revolutionise the management of diseases? J Lifestyle Med. 2019;9(1):1-11. https://doi.org/10.15280/ jlm.2019.9.1.1.

6. Costa G. Sleep deprivation due to shift work. Handb Clin Neurol. 2015;131:437-46. https://doi. org/10.1016/B978-0-444-62627-1.00023-8.

7. Doi Y. An epidemiologic review on occupational sleep research among Japanese workers. Ind Health. 2005;43:3-10. https://doi.org/10.2486/indhealth.43.3.

8. Drake CL, Roehrs T, Richardson G, Walsh JK, Roth T. Shift work sleep disorder: prevalence and consequences beyond that of symptomatic day workers. Sleep. 2004;27:1453-62.

9. Kalmbach DA, Pillai V, Cheng P, Arnedt JT, Drake CL. Shift work disorder, depression, and anxiety in the transition to rotating shifts: the role of sleep reactivity. Sleep Med. 2015;16:1532-8. https://doi. org/10.1016/j.sleep.2015.09.007.

10. Waage S, Pallesen S, Moen BE, Mageroy N, Flo E, Di Milia L, et al. Predictors of shift work disorder among nurses: a longitudinal study. Sleep Med. 2014;15:1449-55. https://doi.org/10.1016/j. sleep.2014.07.014.

11. Gaba DM, Howard SK. Fatigue among clinicians and the safety of patients. N Engl J Med. 2002;347:1249 55. https://doi.org/10.1056/NEJMsa020846.
12. Howard SK, Gaba DM, Smith BE, Weinger MB, Herndon C, Keshavacharya S, Rosekind MR. Simulation study of rested versus sleep-deprived anesthesiologists. Anesthesiology. 2003;98:1345-55. https://doi.org/10.1097/00000542-200306000-00008.

13. Weinger MB, Ancoli-Israel S. Sleep deprivation and clinical performance. JAMA. 2002;287:955-7.

14. Landrigan CP, Rothschild JM, Cronin JW, Kaushal R, Burdick E, Katz JT, et al. Effect of reducing interns' work hours on serious medical errors in intensive-care units. N Engl J Med. 2004;351:1838-48. https://doi. org/10.1056/NEJMoa041406.

15. Lockley SW, Cronin JW, Evans EE, Cade BE, Lee CJ, Landrigan CP, et al. Effect of reducing interns' weekly work hours on sleep and attentional failures. N Engl J Med. 2004;351:1829-37. https://doi.org/10.1056/ NEJMoa041404.

16. Barger LK, Ayas NT, Cade BE, et al. Impact of extended-duration shifts on medical errors, adverse events, and attentional failures. PLoS Med. 2006;3(12):e487.

17. Rogers AE, Hwang W-T, Scott LD, Aiken LH, Dinges DF. The working hours of hospital staff nurses and patient safety. Health Aff (Millwood). 2004;23:20212. https://doi.org/10.1377/hlthaff.23.4.202.

18. Scott LD, Rogers AD, Hwang WT, Zhang Y. Effects of critical care nurses' work hours on vigilance and patients' safety. Am J Crit Care. 2006;15:30-7.

19. Tanaka K, Takahashi M, Hiro H, Kakinuma M, Tanaka M, Miyaoka H. Differences in medical error risk among nurses working two- and three-shift systems at teaching hospitals: a six-month prospective study. Ind Health. 2010;48:357-64. https://doi.org/10.2486/ indhealth.48.357.

20. Needleman J, Buerhaus P, Pankratz VS, Leibson CL, Stevens SR, Harris M. Nurse staffing and impatient hospital mortality. N Engl J Med. 2011;364:1037-45. https://doi.org/10.1056/NEJMsa1001025.

21. Trinkoff AM, Johantgen M, Storr CL, Gurses AP, Liang Y, Han K. Nurses' work schedule characteristics, nurse staffing, and patient mortality. Nurs Res. 2011;60:1-8. https://doi.org/10.1097/ NNR.0b013e3181fff15d.

22. Gander P, O'Keeffe K, Santos-Fernandez E, Huntington A, Walker L, Willis J. Fatigue and nurses' work patterns: an online questionnaire survey. Int J Nurs Stud. 2019;98:67-74. https://doi.org/10.1016/j. ijnurstu.2019.06.011.

23. ANSES Rapport d'expertise Collective. Évaluation des risques sanitaires pour les professionnels exposés à des horaires de travail atypiques, notamment de nuit. Paris: Agence Nationale de Sécurité Sanitaire, Alimentation, Environnement, Travail; 2016. p. $1-408$.

24. Rajaratnam SMW, Barger LK, Lockley SW, Shea SA, Wang W, Landrigan CP, et al. Sleep disorders, health, and safety in police officers. JAMA. 2011;306:256778. https://doi.org/10.1001/jama.2011.1851.

25. Nakata A, Haratani T, Takahashi M, Kawakami N, Arito H, Kobayashi F, et al. Association of sickness absence with poor sleep and depressive symptoms 
in shift workers. Chronobiol Int. 2004;21:899-912. https://doi.org/10.1081/cbi-200038104.

26. Knutsson A, Boggild H. Gastrointestinal disorders among shift workers. Scand J Work Environ Health. 2010;36:85-95. https://doi.org/10.5271/sjweh.2897.

27. Lennernas M, Hambraeus L, Åkerstedt T. Nutrient intake in day and shift workers. Appetite. 1994;8:33242. https://doi.org/10.1006/appe.1995.0060.

28. De Bacquer D, Van Risseghem M, Clays E, Kittel F, De Backer G, Braeckman L. Rotating shift work and the metabolic syndrome: a prospective study. Int J Epidemiol. 2009;38:848-54. https://doi.org/10.1093/ ije/dyn360.

29. Strohmaier S, Devore EE, Zhang Y, Schernhammer ES. A review of data of findings on night shift work and the development of DM and CVD events: a synthesis of the proposed molecular mechanisms. Curr Diab Rep. 2018;18(12):132. https://doi.org/10.1007/ s11892-018-1102-5.

30. Suwazono Y, Dochi M, Oishi M, Tanaka K, Kobayashi E, Sakata K. Shiftwork and impaired glucose metabolism: a 14-year cohort study on 7104 male workers. Chronobiol Int. 2009;26:926-41. https://doi.org/10.1080/07420520903044422.

31. Frost P, Kolstad HA, Bonde JP. Shift work and the risk of ischemic heart disease - a systematic review of the epidemiologic evidence. Scand J Work Environ Health. 2009;35:163-79. https://doi.org/10.5271/ sjweh.1319.

32. Puttonen S, Härmä M, Hublin C. Shift work and cardiovascular disease - pathways from circadian stress to morbidity. Scand J Work Environ Health. 2010;36:96-108. https://doi.org/10.5271/sjweh.2894.

33. van Amelsvoort LG, Jansen NW, Kant I. Smoking among shift workers: more than a confounding factor. Chronobiol Int. 2006;23:1105-13. https://doi. org/10.1080/07420520601089539.

34. Manohar S, Thongprayoon C, Cheungpasitporn W, Mao MA, Herrmann SM. Associations of rotational shift work and night shift status with hypertension: a systematic review and meta-analysis. J Hypertens. 2017;35(10):1929-37. https://doi.org/10.1097/ HJH.0000000000001442.
35. Nurminen T. Shift work and reproductive health. Scand J Work Environ Health. 1998;24(Suppl 3):28-34.

36. Wegrzyn LR, Tamimi RM, Rosner BA, Brown SB, Stevens RG, Eliassen AH, et al. Rotating night-shift work and the risk of breast cancer in the nurses' health studies. Am J Epidemiol. 2017;186(5):532-40. https://doi.org/10.1093/aje/kwx140.

37. IARC Monographs Vol 124 Group. Carcinogenicity of night shift work. Lancet Oncol. 2019;20(8):10589. https://doi.org/10.1016/S1470-2045(19)30455-3.

38. Knauth P. Designing better shift systems. Appl Ergon. 1996;27(1):39-44. https://doi. org/10.1016/0003-6870(95)00044-5.

39. Knauth P. Innovative worktime arrangements. Scand J Work Environ Health. 1998;24(Suppl 3):13-7.

40. Thierry H. Compensation for shiftwork: a model and some results. In: Colquhoun WP, Rutenfranz J, editors. Experimental studies of shiftwork. London: Taylor \& Francis; 1980. p. 449-62.

41. Ladouceur R. Twenty-four-hour shifts for residents. Can Fam Physician. 2013;59(2):123.

42. ACGME Accreditation Council for Graduate Medical Education. Duty hour standard enhancing quality of care, supervision and resident professional development. 2011. https://www.acgme.org/Portals/0/PDFs/ jgme-monograph[1].pdf. Accessed 30 Sept 2019.

43. Park R. Why so many young doctors work such awful hours. The Altantic 21. 2017. https://www.theatlantic. com/business/archive/2017/02/doctors-long-hoursschedules/516639/. Accessed 30 Sept 2019.

44. Bilimoria KY, Chung JW, Hedges LV, Dahlke AR, Love R, Cohen ME, Hoyt DB, Yang AD, Tarpley JL, Mellinger JD, Mahvi DM, Kelz RR, Ko CY, Odell DD, Stulberg JJ, Lewis FR. National clusterrandomized trial of duty hour flexibility in surgical training. N Engl J Med. 2016;374:713-27. https://doi. org/10.1056/NEJMoa1515724.

45. Jena AB, Newhouse RL, Farid M, Blumenthal D, Bhattacharya J. Association of residency work hour reform with long term quality and costs of care of US physicians: observational study. BMJ. 2019;366:14134. https://doi.org/10.1136/bmj.14134. 
Open Access This chapter is licensed under the terms of the Creative Commons Attribution 4.0 International License (http://creativecommons.org/licenses/by/4.0/), which permits use, sharing, adaptation, distribution and reproduction in any medium or format, as long as you give appropriate credit to the original author(s) and the source, provide a link to the Creative Commons license and indicate if changes were made.

The images or other third party material in this chapter are included in the chapter's Creative Commons license, unless indicated otherwise in a credit line to the material. If material is not included in the chapter's Creative Commons license and your intended use is not permitted by statutory regulation or exceeds the permitted use, you will need to obtain permission directly from the copyright holder.

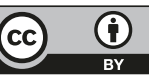

